\title{
Mother-Daughter Conflict among 18 - 21 Years Old Adolescents: Structure, Causes and Management
}

\author{
Bennie Berkeley, Michelle Thomas-Mason \\ University of the West Indies, St. Augustine, Trinidad and Tobago \\ Email: Bennie.Berkeley@sta.uwi.edu
}

Received 6 April 2015; accepted 25 April 2015; published 30 April 2015

Copyright (C) 2015 by authors and OALib.

This work is licensed under the Creative Commons Attribution International License (CC BY). http://creativecommons.org/licenses/by/4.0/

c) (i) Open Access

\begin{abstract}
This research examines mother-daughter conflict in freshmen/first-year female students (18 - 21 years) enrolled at the Faculty of Social Sciences (FSS), University of the West Indies (UWI), St. Augustine, Trinidad. The concentration on mothers in full or part-time paid employment is reinforced by Pickhardt [1] who argued that mothers are more comfortable than fathers in family conflict. The purpose of the study was to describe the structure of a typical mother-daughter conflict by examining its causes and management. Using a sample of 23 (sociology and psychology) students, 10 open-ended questions were posed. The major questions were: Why do you get into conflict with your mother? What or who is to blame? What is a typical conflict like? What effects does conflict have on you? How are these conflicts resolved or managed? A phenomenological approach was adopted. Purposive sampling was employed by recruiting only females $(18-21)$ involved in at least one family conflict in the last month (September, 2014). First the findings indicate five (5) features of mother-daughter conflict: Conduct (act or speech), Response, Reaction, Intensification and Containment (CRRIC). The second is that issues of home and school are the main sources of conflict and that at the end daughters fare less well compared to mothers. Future research includes mother-son conflict and the parenting adolescent/young adult children.
\end{abstract}

\section{Keywords}

Structure of Conflict, Causes and Containment

Subject Areas: Education, Psychology

\section{Introduction}

\subsection{Family and Conflict}

Studies by functionalists such as Murdock cited in Haralambos, Holborn \& Heald [2] and Parsons \& Bales [3]

How to cite this paper: Berkeley, B. and Thomas-Mason, M. (2015) Mother-Daughter Conflict among 18 - 21 Years Old Adolescents: Structure, Causes and Management. Open Access Library Journal, 2: e1491. 
have long depicted the nuclear family as ideal, because it fulfills functions for the individual and the society as a whole. For instance Murdock claimed that the family ensures socialization of young children, and economic, sexual gratification and reproduction between spouses of different sexes. Parsons \& Bales [3] recognized that in the mid-twentieth century the family was under strain and thus more likely to be affected by divorce. In spite of this they were optimistic that rising divorce rates would stabilize and that remarriage would restore the nuclear family. Like most functionalists they assumed that conflict is inimical to a happy healthy family and almost completely "wrote it away".

Critics like McClelland [4] and Parasuraman \& Simmers [5] have counter-argued that the family is far from happy and stable. McClelland claimed that family stress produces family dysfunction arising from hostile parenting and poverty. Parasuraman and Simmers argued that when at least one spouse is self-employed there are higher levels of family conflict.

The family is blamed for many of the social ills (crime and delinquency) plaguing Trinidad society, Phillips [6]. In studying delinquency in Junior Secondary schools, Phillips found that sexual, physical and verbal abuses were significant stressors associated with school violence. Furthermore students were affected by negative parent behavior like fighting and neglect. Research conducted in Jamaica supported the position that students exposed to violence in the home and community are prone to aggression and violence in school (Meeks Gardner \& Powell [7]).

In the last decade of the twentieth century, psychological research revealed a diversity of factors contributing to family conflict. Duxbury et al. [8] argued that women more than men face work overload-dual burden syndrome. They are likelier to feel strained and stressed by the double burdens of working at home and working in the labor market. For this reason students who were at odds with their mothers and who lived on halls were selected. We wanted to gain an appreciation of the nature of mother-daughter conflict for working mothers. Fuligni [9] focused on parent-adolescent conflict and suggested:

Despite holding different beliefs about parental authority and individual autonomy, adolescents from all generations and cultural backgrounds reported similar levels of conflict and cohesion with their parents. Discussion focuses on the relative importance of cultural beliefs and social settings in shaping the nature of parent-child relationships during adolescence [9].

A detailed examination of local literature on family conflict revealed no noted examples of mother-daughter conflict, mother-son or father-child conflict with sons or daughters. This study would add to the scholarship on family life in Trinidad and Tobago.

\subsection{Mother-Daughter Conflict}

Laursen [10] concluded that daughters experienced more interpersonal conflict with parents (mothers and fathers) than sons. Predominantly it occurs in single-mother households of African, European and Cuban American ethnicities. It is widely accepted that there is more conflict between single-parent divorced mothers and their children than in any other parenting arrangement (Walter \& Hennig [11] and Baer [12]). The main reason is that lone-parent family structure presents more opportunity for mother-child conflict.

Maternal employment and socioeconomic status (SES) were commonly cited causes. In the Caribbean rates of single-parenting and single-mother parenting are relatively high. In the region as a whole between 30 and 50 percent of African-Caribbean families are female headed. Grenada (45.3\%), Barbados (42.9\%) and Jamaica (33.8\%) respectively show significant rates (Massiah [13]). Coupled with high rates of matrifocality (mother centeredness), the number of females in paid employment has increased as a result of greater educational opportunities and trends towards greater gender equity (St. Bernard [14]). These figures warrant an examination of the impact of maternal employment and step fathering on adolescent girls' behavior. In this study our focus is nuclear families with working mothers.

\subsection{Defining Adolescence}

Thorndike et al. [15] argued that adolescents are aged 12 - 21. In this study 18 was the lower age limit, and 21 was the upper. In Trinidad and Tobago, because 18 is the legal adult age, there was no need for parental consent; all participants were eligible for inclusion having already attained age of 18 before September 2014.

\section{Method}

The data were collected through purposive sampling. First a pilot study was conducted. A sample of two partic- 
ipants (one male and one female aged 18 - 21) was selected. They revealed being in conflict with their mothers and opted to live in residential hall or in an apartment complex in close proximity to UWI to escape the trauma associated with mother conflict.

In the actual study we decided to explore daughters' perspectives in order to "hear" their voice. Sons' perspectives would be explored in future research. 23 females were interviewed, 10 lived on hall and 13 in apartments. By this number we experienced data saturation.

Interviews lasted between 40 minutes and one hour. Issues explored included the nature of a typical conflict, causes of conflict, effects of conflict and conflict management. Structural conflict, endogenous or relational conflict theory was employed to ascertain daughters' perspective, i.e. mothers' views were not taken into account.

All interviews were transcribed verbatim and read three times before coding. In each interview no fewer than 20 significant statements were identified and compared. Categories and themes of meaning were developed from 150 codes. One radical departure from phenomenological data analysis expounded by Creswell [16] was deconstruction of meanings of conflict. The purpose was to ascertain the nature of, main causes and management of mother-daughter conflict.

\section{Findings}

\subsection{The Structure of a Typical Conflict Experience}

Comparison of significant themes of meaning produced five (5) enduring features of the structure of a typical mother-daughter conflict. The first is conduct-a speech or act a daughter committed e.g. "I did not do the dishes, I broke curfew or I did not do well in examinations this semester". The second is (mothers') response to conduct. Mothers were thought to be "going over the edge", acting emotionally or being out of touch. The third is daughters' reaction to mothers' response. Daughters sometimes retorted: "It was unintentional” or "why are you behaving this way mom". The fourth is intensification-mothers take physical or verbal action attempting to save face and maintain power and control. The social context influences reciprocated action. Conflict intensity depended on a number of factors. The most pervasive was third party presence and/or intervention. Overall the intensification of conflict was kept in check in the presence of a third party. Finally the containment phase occurs when events climax before or dissipate. There is no conclusive conflict resolution. Participants felt that it worked to their mothers' advantage. It was the catalyst for further conflict. Member checks confirmed this five part structure.

\subsection{Institutional Sources of Parent-Child Conflict}

Two major institutional sources of conflict were identified: the home and the school. By far the home was more likely to provide opportunities for mothers and daughters to "fight". School related conflict revolved around low or failed academic performance and perceived negative influences from peers who adversely affected school work. Flannery [17] corroborates three sources of conflict. He found that curfew, grades and personal appearance were significant causes.

\subsubsection{Home Generated Conflict}

Data coding produced a number of categories which summed up common experiences. Table 1 illustrates that the most prevalent sources of conflict were dress, disrespect, disobedience, chore completion curfew violation and sibling conflict. Adolescents claimed to become emotionally upset when mothers scolded them for disrespect and disobedience. Disrespect was interpreted in verbal actions like answering back (even when an answer was expected), modified or harsh tones of voice and mannerisms. Disobedience involved failure to carry out mothers' desires that daughters perceived to be trivial, inappropriate or unnecessary. Chore completion, though inherently bound up with disobedience, stood out as the most frequently fought over issue. Daughters reported being reprimanded for unsatisfactory completion of chores such as washing up after a meal. Routine acts like stacking dishes and leaving drawers open were heavily policed.

Breaking curfews met with severe reprimand. Sometimes mothers refused to take calls intended to account for late coming. Participants felt angry and sensed lack of trust for their judgment and initiative when mothers reacted dismissively to their attempts at justifying late coming.

Daughters reported being perplexed over their mothers' role in sibling rivalry. Elder siblings felt disrespected 
Table 1. Main sources of conflict and significant statements.

\begin{tabular}{lll}
\hline Source of Conflict & \multicolumn{1}{c}{ Category } & \multicolumn{1}{c}{ Significant Statement (examples) } \\
\hline & Inappropriate dress & You are inappropriately dressed! \\
& Disrespect & Who are you speaking to like that! \\
The Home & Disobedience & I told you not to do it and you did! \\
& Chore completion e.g. washing dishes & Look at the mess; you have not done the dishes! \\
& Breaking curfew & You were supposed to get home by 11.00 pm, where were you? \\
& Sibling conflict & You are supposed to look out for your younger brother/sister; \\
& & why didn't you! \\
The School & Low grade & You are an embarrassment! \\
& Peer group influence & Did you study for your exam/s? \\
\end{tabular}

when mothers stood up for younger siblings in times of sibling conflict. Too often they felt that they were blamed for not diffusing conflict with a brother or sister.

Association between personal identity/self-expression and dress or comport was demonstrated. The popular belief is that parents negatively evaluated contemporary clothes and styles of hair. There were noted gender differences in parental attitudes toward sons' and daughters' dress and general appearance. Because they were less heavily policed participants thought that their brothers were cynical or blasé towards sexism. Daughters resented mothers' leniency towards boys and reported that a great deal of sexism and double standards in family discourse.

Mother-son conflict was reported to occur over boys' styles of dress such as wearing baggy trousers in formal spaces like hospitals or schools. Wearing them at informal events such as a party or sport did not attract negative sanction. Some mothers regarded modern dress styles as displays of loose morals and an absence of wholesome family and personal values. This contrasted starkly with the young people's perceptions that they were trendy, fashionable and comfortable. There was very little evidence of peer pressure on youths to keep up with the trendiest name brands advertised by their favorite sport and entertainment celebrities like Beyonce, Jordan and JLo.

\subsubsection{Schooling and Conflict}

Underachievement and failure in academics (college or university studies) produced conflict. In most instances mothers learnt of failure or low grades by overhearing conversations with friends or siblings. In other words, they were thought to have breached daughters' privacy right. Mothers who acted on knowledge obtained by breach of privacy initiated conflict if they commented on daughters' academic performance negatively or angrily.

Peer pressure was the most powerful perceived influence on academic achievement. It was believed to be a strong predictor of conflict. Like Montemayor [18] they believe that peers provided a safe haven; a space where they could be heard without being judged or battered emotionally and psychologically.

Daughters felt that mothers did not take into account significant factors like professor attitude and teaching style, and their learning style. It was mothers' belief that their daughters should be capable of addressing poor teaching styles without their intervention. Participants were concerned that these factors (teaching and learning styles) were most influential to success but mothers trivialized or wrote them off. Students claimed that mothers do not understand the competitiveness of university educational processes; sometimes comparing, unrealistically, high school and university academic standards. They did not consider the intensity and scope of university work. Mothers were perceived to be "out of touch" with the goings-on at university; a perception that held true for all levels of maternal education.

This results of this study were support by Allison [19] who claimed that during adolescence parents and their young adult children frequently disagree over their schooling and failure to take responsibility for housework and domestic tasks such as washing up after meals, doing laundry and making beds. 


\subsection{Conflict Containment}

Parental education made little difference to conflict containment. Mothers with tertiary qualifications were perceived to be as difficult as less well educated mothers (primary or secondary educated only) to get along with. Adolescents viewed their mothers as having one thing in mind; the maintenance of control and authority over them. Conflict containment was both authoritarian and democratic. It produced latency or deferral of conflict to a future time. There was little, if any, resolution.

\subsubsection{Authoritarian Containment}

This is divided into two forms: physical and verbal/emotional. They are part of mothers' artillery for containing conflict. Daughters are rendered powerless and made to feel resentful and disrespected.

\section{1) Authoritarian Physical}

Containment is involuntary and exhibited when mothers engage in destructive anger behaviors (Wolf \& Poshee [20]) such as hitting, slapping or shoving (a coercive strategy) to enforce conformity and maintain control. Physical containment was most frequently employed in fathers' absence. Fathers had a mediating effect in mother-daughter conflict. Sometimes conflicts subsided only to resume later in their (fathers') absence.

\section{2) Authoritarian Verbal/Emotional}

Mothers would shout at, talk down to and say hurtful things to humiliate their daughters. Participants felt that being shouted at produced loss of self-esteem and self-belief. It was believed that mothers' style of punishment was over reactive and resulted from the frustration produced by working hard at home and in the labor market. Some support for this finding was obtained. In a longitudinal study of mother discipline O'Leary et al. [21] also found mothers to be over-reactive. Daughters who empathized with their mothers claimed they were not to blame and suggested that authoritarian containment styles made conflict virtually invisible though it was ever present. The goal was mother hegemony not resolution of conflict. Mothers exercised a petty dictatorship in family matters.

\subsubsection{Democratic Containment}

Democratic containment style was used less frequently. It can be equilibrated with family politics. It enabled dialogue between disputants as mothers and daughters voiced their concerns, expressed remorse for inappropriate conduct and reached mutual, (though artificial) agreement. Adolescents described consensus as artificial since they did not believe that their mothers were satisfied with cooperative problem resolution techniques. Of all forms of containment it comes closest to supportive parenting suggested by Pettit et al. [22].

On the whole democratic containment occurred in the presence of a third party (usually fathers, grandparents or other relatives). Third parties were not involved directly in conflict. Their presence was a significant mediating force that increased daughters' bargaining power while decreasing mothers'. During this time mothers' reactions were carefully scrutinized so that sometimes it swung the balance of power toward daughters.

\section{Discussion}

Several issues and themes of meaning were induced from the data. The most persuasive were hegemony vs. autonomy, conflict complexity, indexicalizing conflict and youth culture. The common thread running through these issues is that top-down structures of authority within the family combine age and gender relationships resulting in young females at the bottom of the power structure and older males the top. Despite the ideology of female liberation some women still practice female subordination and male privileging in family relationships. The family contains built-in structures of inequality that leave women and girls feeling vulnerable. Females often turn against one another as they struggle for dominance and leadership within their gender.

\subsection{Hegemony vs. Autonomy}

The study concurs with Mc. Clell and [4] that the nuclear family is far from happy and stable. This is the case because when mothers and daughters fight; mothers seek hegemony, daughters seek autonomy. Mother ideological or coercive dominance reflects hegemony and dictatorship. Family politics weighed heavily in mothers' favor. Laursen, Coy \& Collins [23] suggest that adolescent independent seeking behaviors results in disequilibrium in mother-daughter relationships. However, we did not explore the state of mother-daughter relationships 
during childhood, puberty or early adolescence and therefore cannot verify the extent of disequilibrium in relationships with their mothers.

\subsection{The Complexity of Conflict}

We concur with Yau \& Smetana [24], Özmete \& Bayoğlu [25] and Montemayor [26] that adolescent-parent conflict is multifaceted and comprises personal and family issues. Personal issues like dress and peer influences were strong predictors of mother-daughter conflict. Family issues included sibling rivalry and chore completion. In this study we found that conflict is iterative i.e. current conflict often draws on past resolved or unresolved conflict. In addition, conflict is multi-layered i.e. contains several interlocking issues e.g. disagreement over breaking curfew includes arguments of peer influence, challenging authority and concerns for physical safety. The relationship between sex, drugs and family conflict was not explored; we wished to avoid intruding too far into students' personal life.

\subsection{Indexicalizing Conflict}

Context had great impact on the intensity and direction of conflict and its containment. In other words conflict is indexed. The context (place, time and actors) was a significant predictor of its causes and consequences. Mothers perceived all conflict to be significant. Their style of containment differed according to context-third party presence, emotional state, and location. Conflict in public places (supermarket, park or school) was deferred for a private space and time. Sometimes they were picked up in the home later on, often accompanied by issues in past conflict not managed to their satisfaction (complexity). Daughters appreciated third party presence and public spaces and employed techniques of neutralization to deal with the emotional burden of conflict. They employed neutralizing techniques like "it was no big deal”, "no one got hurt”, "mommy over-reacted”.

\subsection{Youth Culture and Family Conflict}

The phenomenon of youth culture can explain the perceived mother-child (daughter/son) generation gap. The extension of schooling and economic dependence on parents and state for support has exacerbated the generation gap between mothers and young adult daughters. However, we see this through postmodern lenses. It is not universal per se but a form of adaptation to lack of financial and familial independence. However, we did not explore whether or not youth culture was as distinguishable as Brake [27] claimed it to be in the 1950s. In spite of incidences of mother-son conflict an institutionalized sex-class system in the family favored boys. Axinn et al. [28] confirmed gender double standards in parenting without going so far as claiming a sex-class system. However, we found no cogent evidence of hegemonic masculinity described by Connell [29].

\section{Conclusions}

This inquiry into mother-daughter conflict, intended to gather data about the experiences of adolescent girls in full-time academic studies, produced more than we expected. From adolescents' perspective it was found that a typical experience consists of CRRIC-conduct (act or speech), response, reaction, intensity and containment. It was discovered that home and school issues were the main sources of mother-daughter conflict. Participants explained that containment, a quasi-management phenomenon, featured significantly in mother-daughter conflict.

According to Pickhardt [1] mothers socialized to value communicative emotionally intense relationships frequently confront conflict directly. It is not that fathers and adolescents do not engage in conflict but that fathers may avoid it more than mothers. However, we were able to understand family dynamics profoundly. In terms of parenting we learnt that no matter how old children become, mothers seek to maintain control especially over dependants. Evidence suggests latent or unintended family functions such as conflict and "class" or personal struggle between parents and their young adult children.

Stark differences in gender behaviour were noted in fathers' and mothers' style of conflict management. This suggests that within the domestic sphere, patriarchy is maintained and represented symbolically by "cooling out" or "heating up" of father and mothers respectively. Gender differences were noted in mothers' favourable attitude towards sons over daughters.

Despite the small sample size we believe that the data were sufficient to generate new hypotheses about parenting and family life. For instance we hypothesized that conflict management is equated with conflict contain- 
ment, gender differences in parental conflict management styles (mothers/indirect and fathers/direct), and father role (or third party) mediates mother-daughter conflict. We know there are other types of family conflict like sibling-sibling, father-daughter, father-son and mother-son. However, these will be investigated in future research.

Structural conflict theory was appropriate for this study; family conflict was instrumental borne out by struggle for hegemony. There was strong support for the view that the family is far from happy and stable. Our study can be summed up by this statement "families are paradoxical, containingsocial structural hierarchies that regulate power characterized by processes that intensify conflicts" (Farrington and Chertok [30]).

\section{References}

[1] Pickhardt, C.E. (2011) Surviving Your Child's Adolescence: How to Understand, and Even Enjoy the Rocky Road to Independence? Jossey-Bass, San Francisco.

[2] Murdock, G.P. (2004) In: Haralambos, M., Holborn, M. and Heald, R., Eds., Sociology: Themes and Perspectives, 6th Edition, Harper Collins, Hammersmith.

[3] Parsons, T. and Bales, R.F. (1998) Family, Socialization and Interaction Process. Free Press, Glencoe III.

[4] McClelland, A. (2000) Impacts of Poverty on Children, Brotherhood Comment, Brotherhood of St. Laurence, Australia.

[5] Parasuraman, S. and Simmers, C.A. (2001) Types of Employment, Work-Family Conflict and Well-Being: A Comparative Study. Journal of Organizational Behavior, 22, 551-568.

[6]

[7] Meeks Gardner, J. and Powell, C. (2005) Aggressive Youth and Youth Experiences of Violence in Kingston, Jamaica. Journal of Children's Issues, 2, 71-81.

[8] Duxbury, L., Higgins, C. and Lee, C. (1994) Work-Family Conflict: A Comparison by Gender, Family Type, and Perceived Control. Journal of Family Issues, 15, 449-466. http://dx.doi.org/10.1177/019251394015003006

[9] Fuligni, A.J. (1998) Authority, Autonomy, and Parent-Adolescent Conflict and Cohesion: A Study of Adolescents from Mexican, Chinese, Filipino, and European Backgrounds. Developmental Psychology, 34, 782-792. http://dx.doi.org/10.1037/0012-1649.34.4.782

[10] Laursen, B. (2005) Conflict between Mothers and Adolescents in Single-Mother, Blended, and Two Biological-Parent Families. Parenting: Science and Practice, 5, 347-370. http://dx.doi.org/10.1207/s15327922par0504_3

[11] Walter, L.J. and Hennig, K.H. (1997) Parent/Child Relationships in Single-Parent Families. Canadian Journal of Behavioural Science, 29, 63-75. http://dx.doi.org/10.1037/0008-400X.29.1.63

[12] Baer, J. (1999) The Effects of Family Structure and SES on Family Processes in Early Adolescence. Journal of Adolescence, 22, 341-354. http://dx.doi.org/10.1006/jado.1999.0226

[13] Massiah, J. (1982) Women Who Head Households. In: Massiah, D., Ed., Women and the Family, Institute of Social and Economic Policy, Cave Hill.

[14] St. Bernard, G. (2003) Major Trends Affecting Families in Central America and the Caribbean. Division of Social Policy and Development, Department of Economic and Social Affairs, Program on the Family, United Nations.

[15] Thorndike, A., Ferris, T.G., Stafford, R.S. and Rigotti, N.A. (1999) Rates of U.S. Physicians Counseling Adolescents about Smoking. Journal of the National Cancer Institute, 91, 1857-1862. 3http://dx.doi.org/10.1093/jnci/91.21.1857

[16] Creswell, J. Research Design: Qualitative, Quantitative and Mixed Methods Approaches. 2nd Edition, University of Nebraska, Lincoln.

[17] Flannery, B. (2013) Sources of Conflict between Parents and Teenagers. Parent and Teens Sources of Conflict.

[18] Montemayor, R. (1982) The Relationship between Parent-Adolescent Conflict and the Amount of Time Adolescents Spend Alone and with Parents and Peers. Child Development, 53, 1512-1519. http://dx.doi.org/10.2307/1130078

[19] Allison, B.N. (1999) Parent-Adolescent Conflict in Early Adolescence: Research and Implications for Middle School Programs. Journal of Family and Consumer Sciences Education, 18.

[20] Wolf, K.A. and Foshee, V.A. (2003) Family Violence, Anger, Expression Styles and Adolescent Dating Violence. Journal of Family Violence, 18, 309-316. http://dx.doi.org/10.1023/A:1026237914406

[21] O’Learn, S.G., Slep, A.M.S. and Reid, M.J. (1999) A Longitudinal Study of Mothers' Overactive Discipline and Toddlers’ Externalizing Behavior. Journal of Abnormal Child Psychology, 27, 331-341. http://dx.doi.org/10.1023/A:1021919716586 
[22] Pettit, G.S., Bates, J.E. and Dodge, K.A. (1997) Supportive Parenting, Ecological Context, and Children's Adjustment: A Seven-Year Longitudinal Study. Child Development, 68, 908-923. http://dx.doi.org/10.2307/1132041

[23] Laursen, B., Coy, K.C. and Collins, W.A. (1998) Reconsidering Changes in Parent-Child Conflict across Adolescence: A Meta-Analysis. Child Development, 69, 817-832. http://dx.doi.org/10.1111/j.1467-8624.1998.00817.x

[24] Yau, J. and Smetana, J.G. (1996) Adolescent-Parent Conflict among Chinese Adolescents in Hong Kong. Child Development, 67, 1262-1275. http://dx.doi.org/10.2307/1131891

[25] Özmete, E. and Bayoglu, A.S. (2009) Parent-Young Adult Conflict: A Measurement on Frequency and Intensity of Conflict Issues. The Journal of International Social Research, 2, 313.

[26] Montemayor, R. (1986) Family Variation in Parent-Adolescent Storm and Stress. Journal of Adolescent Research, 1, 15-31. http://dx.doi.org/10.1177/074355488611003

[27] Brake, M. (2013) Youth Cultures and Subcultures: Sex and Drugs and Rock 'n' Roll. Routledge, Abington.

[28] Axinn, W.G., Young-Demarc, L. and Caponiro, M. (2011) Gender Double Standards in Parenting Attitudes. Social Science Research, 40, 417-432. http://dx.doi.org/10.1016/j.ssresearch.2010.08.010

[29] Connell, R.W. (2005) Masculinities. 2nd Edition, University of California Press, Berkeley.

[30] Farrington, K. and Chertok, E. (1993) Social Conflict Theories of the Family. In: Boss, P.G., Doherty, W.J., LaRossa, R., Schumm, W.R. and Steinmetz, S.K., Eds., Sourcebook of Family Theories and Methods: A Contextual Approach, Plenum, New York, 357-384. 